\title{
ACERCA DE UNA RECUPERACIÓN EN CLAVE FILOSÓFICA DE 338171 T. E. DE Victoria OCAMPO
}

\author{
Fernando G. Martin De Blassi*
}

\begin{abstract}
"Porque nadie habló con más dureza que él de sus propias debilidades. Nadie fue a un mismo tiempo actor y espectador de su vida como fue él. Y el espectador era implacable con el actor. Y el actor era cruel con el espectador. Si el actor se permitía un ademán que no fuera justo, que no fuera fiel a la verdad y adecuado a la circunstancia, el espectador se lo echaba en cara; si el espectador se permitía una palabra que ningún ademán del actor acompañaba o ni justificaba, el actor se le reía amargamente".
\end{abstract}

Con palabras similares o incluso de mayor calibre dramático que estas, Victoria Ocampo (1942: 20) ha mostrado la fascinación que significó para ella la figura de Thomas Edward Lawrence. El encuentro entre ellos surge como pensar poético que se impone develar una gesta personal íntima, conviene a saber, el conflicto moral de un hombre cuyo destino le depararía múltiples rutas mundanas. Sin embargo, aun cuando ambos fuesen contemporáneos, ese acercamiento nunca llegó a concretarse cara a cara. Sólo se dio cuando Ocampo hubo leído Los siete pilares de la sabiduría (Lawrence, 1944). A partir de allí, nace un vínculo anímico peculiar, ostensible en el texto que ella tituló de un modo cifrado, no asequible para la conciencia inmediata: 338171 T. E. Este código, por cierto, no carece de justificación pues la escritora se atiene mediante ello a respetar el afán de olvido y anonimato deseado por Lawrence. Los fonemas $T$. E. se refieren a las iniciales de su nombre de pila y al modo como él en persona había pedido ser nombrado por sus amigos más íntimos, la clave 338171 representa el número de registro que lo identificada como soldado de la RAF. Personaje polifacético: arqueólogo, escritor, soldado anónimo, hallándose en suelo inglés y queriendo olvidar su célebre condición, se oculta bajo el incógnito que le proporciona esa numeración militar.

* UNCuyo-CONICET. Mendoza, Argentina. martindeblassi@hotmail.com 
El asombro de Ocampo por Lawrence ha sido recuperado en nuestros días gracias a la investigación de Rosalía Centeno (2014) quien, sumándose al conjunto de estudiosos sobre la narrativa de la escritora argentina, ha procurado dilucidar desde una mirada filosófica el mensaje de 338171 T. E. El propósito perseguido por Centeno estriba en iluminar la actividad del pensar en y desde un poetizar originario. Afirma que pensar y poetizar se corresponden con filosofía y canto, es decir, con filosofía y arte; y advierte, entonces, que esta conjunción de sistemas de significancia aflora una y otra vez en 338171 T. E. Lejos de excluirse mutuamente como términos antitéticos, los polos del par mentado revelan en el texto de Ocampo el contrapunto de un "pensar poético" y, a fortiori, de un "poetizar pensante", dimensiones tan caras al ejercicio filosófico de nuestro tiempo (cfr. Ricoeur, 1999).

Por lo que respecta al contenido del presente volumen, sus condiciones de posibilidad se circunscriben a dos horizontes que configuran tanto su comprensión cuanto su sentido y alcance. En primer lugar, el horizonte literario, correspondiente al escrito de 338171 T. E. y que se determina como la materia de análisis propiamente dicha; por otra parte, el horizonte estrictamente filosófico, representado por la obra erudita de E. Albizu, que constituye un rico marco teórico sobre cuya base se cimenta estructural y conceptualmente el estudio en cuestión.

Centeno muestra que, en líneas generales, la producción de Ocampo encuentra su hilo conductor a partir del "discurso del yo". Dentro del encuadre literario, este concepto eje es entendido por la crítica ensayística como sinónimo de "literatura autobiográfica" o de "literatura intimista". En este tipo de textos se descubre una especial apropiación del discurso auto-referido. De allí la apelación esencial a la presencia del lector: un otro a quien se lega un testimonio de vida. En consonancia con lo definido previamente por la especialista C. Viñuela (2004), Centeno destaca una raíz anímica, generadora del peculiar estilo literario practicado por Ocampo, y la denomina con el predicado de etimon, esto es, la fuente y motivación de cuanto hizo e hiciera la notable escritora. El etimon de todo autor patentiza el núcleo verdadero, puesto que íntimo, de cuyo centro vital emergen el estilo, la temática y el modo de trabajar una obra. Atañe, sin duda, a una dimensión mucho más amplia que la psicológica, pues tal acontecer anímico envuelve dentro de sí - a la vez que asume en conjunto - los estratos afectivo y representativo del propio conocimiento. 
Sobre la base de este fundamento, el concepto de "raíz humana originaria" comprende una de las formas plausibles para definir etimon, en la medida en que sugiere un momento fundacional, capaz de proyectar toda una gama de posibilidades donde el yo poético se auto expresa en su poíema. En este nivel, como desde su propia interioridad fecundante, el yo-sujeto asume libremente el mundo real como lo otro de sí mismo y lo hace en virtud "de un engendrar en belleza" (Platón, 206 b). Tal experiencia acaece gracias a un tiempo recorrido y consumado, cada vez, a lo largo de la dialéctica que se opera entre el sucesivo transcurrir sympathético (chrónos) y la síntesis de un dis-currir rememorante (anámnesis-kairós).

La perspectiva egotista, que abreva en lo profundo del ser y cataliza desde él la experiencia emergente en la escritura, constituye el punto de partida para encarar y aproximarse desde allí a la obra misma de la escritora argentina. Siguiendo nuevamente a Viñuela, Centeno muestra que, pese a su diversidad, la unidad de los escritos de Victoria está caracterizada por esa actitud de índole egotista - no egoísta ni mucho menos hedonista - pues revela un temple de ánimo conformador, desde el cual la célebre escritora teje su expresión personal. Esta actitud ha de ser ponderada, a su vez, como el fruto de un conflicto no resuelto en el hondón de su alma: una encrucijada tal que, por su mismo carácter testimonial, se proyecta dinámicamente en sus escritos. A partir de esta original perspectiva de análisis, el trabajo de Centeno hace ver que el conflicto abrigado por Victoria la abarca por entero y la conduce, con renovados esfuerzos, en pos de una lectura de sí misma siempre más clara, a fin de dilucidar el problema y en consecuencia poder superarlo. Ello no obstante, según evidencia la propia obra de Ocampo, pareciera que el anhelo de alcanzar aquella meta nunca se habría logrado felizmente. La crítica posterior, incluso cuando haya estudiado el posicionamiento de Ocampo frente a su realidad acuciante, no sondeó en lo radical de su etimon. Frente a un estado de la cuestión como este, el trabajo del que aquí se trata adquiere un estatuto original pues no sólo aborda la escritura de Ocampo desde una mirada hasta el momento inexplorada, esto es, la filosófica, sino que también lo hace intentando penetrar en el brete existencial de la escritora desde los fenómenos que ella va revelando en su obra, como las diferentes manifestaciones de una misma unidad sustancial. 
Con respecto a su estructura, el libro de Centeno se organiza en cinco capítulos cuyos títulos y divisiones son altamente significativos. En primer lugar, ella afinca su investigación en el postulado axial del encuentro intersubjetivo entre Ocampo y Lawrence, pues a partir de allí se va desplegando la posibilidad de delinear la silueta tanto propia como ajena, en cuanto medio de expansión del yo involucrado en la labor poética. Tal correlación de experiencia y mundo es, justamente, el principio rector que orienta la exégesis de Centeno sobre 338171 T. E. Por otra parte, ella muestra una aguda capacidad sinóptica al recortar el objeto de interés al que se circunscribe su análisis, y hacer girar en torno a él el componente integral de la personalidad de los involucrados. De esta manera, el recurso procedimental empleado por Centeno posibilita aunar en parejo equilibrio esas dos figuras convergentes: la del coronel Lawrence a la vez que la de Victoria. El comportamiento heroico y agónico de aquel causa en Ocampo una impresión tal que ella intentará develar, por medio de sus páginas, el conflicto moral padecido por Lawrence. La gesta libertaria de T. E. a favor del pueblo árabe se convierte, por tanto, en el reflejo de otra campaña que transcurre en los recovecos de su interioridad. Es la gesta de una voluntad irrestricta, que se impone la tarea de dejar constancia de su afán de inmortalidad en Los siete pilares de la sabiduría. Ocampo reconoce en este libro, como inspiración fundamental, la necesidad de T. E. de dejar su huella en el tiempo. Winston Churchill, amigo de T. E., lo retrata en un encomio que reza de la siguiente manera:

“Sobre T. E. Lawrence el mundo moderno no ejercía la menor presión. Solitario, austero, inexorable, se movía en un plano aparte, por encima de los demás mortales. Sus virtudes eran sobrehumanas. Su nombre vivirá en la historia, en las letras inglesas, en los anales de la guerra, en las tradiciones de la Royal Air Force y en las leyendas de Arabia".

En la enigmática figura de Lawrence, Victoria no sólo reconoce genialidad literaria sino también cualidades singulares: fuerza de convicciones, impertérrita voluntad de ejercerlas contra el mundo y aun contra sí mismo. Ella deja asentado este sentimiento de admiración en varios tomos de sus Testimonios: III, V, VI, VII y IX. En dichos volúmenes, analiza con detenimiento los orígenes de T. E. Allí encuentra decisiva la ejemplar relación con su madre, de quien Lawrence habría heredado un fuerte complejo de culpabilidad y puritanismo. Recoge también 
otras versiones de T. E. junto con los innumerables estudios referidos al epistolario de su autoría, que él había dirigido a su familia, amigos y conocidos.

En este punto radica el papel medular que juega el cultivo de la memoria dentro de la creación literaria de Ocampo. Los recuerdos de su vida son una cantera inagotable, colmada de ausencias. Tal como asevera Centeno, la memoria de la escritora argentina se dirige pronta hacia el rescate de su pasado. Emprende una marcha sin concesiones a la zaga de aquellos momentos atesorados por ella, entre los cuales descuellan las evocaciones de la infancia por ser el tiempo original, aéreo y diáfano donde se funda la matriz que adopta toda experiencia ulterior. El pasado recorrido, unificado y, por fin, reconocido es el espacio donde la actividad literaria de Ocampo se mueve a modo de ejercicio permanente de rememoración. Este ámbito, por cierto, excede a menudo los niveles de la consideración individual y toca los límites de la experiencia histórica. El pasado se convierte en ese desde donde todos los hechos y momentos, todos los instantes, se hallan dotados de una presencia nostálgica que la memoria, tanto singular como universal, los rescata del oscuro olvido.

Centeno categoriza el acto de rememoración como un movimiento constante que el fluido pensar ejerce en Ocampo. El pasado, en particular aquello que fue plenitud, gozo, acmé no es sólo un tiempo perdido, un principio de ausencia, sino también un tesoro pasible de ser recobrado por la fuerza de la narración. El nuevo presente, enriquecido por la búsqueda de permanentes recuerdos, implica paradojalmente la creación de un nuevo tiempo que, en la escritura de Ocampo, adquiere visos de una restauración poética de lo real. Desde esta gesta, que sólo sabe acometer su empresa cuando retorna a los dominios amplísimos del mundo interior, surge el testimonio en cuanto ejercicio vital de rememoración.

Asimismo, Centeno interpreta que entre ambos personajes se registra una peculiar simbiosis de la voluntad, de la inteligencia y de la afectividad, no exenta de contradicciones ni complejidades. Muestra que, tanto para Victoria como para Lawrence, no hay otro correlato efectivo del éxtasis de la voluntad sino aquel que reside en su agonía final: la colisión indefectible sufrida entre el ansia de plenitud y los límites de la propia finitud. La voluntad de que se trata desprecia la vaciedad de todo discurso mundano. Como el gozo al que suplanta, requiere y exige para sí la eternidad. Sin embargo - estima Centeno - tal conciencia moral, 
poco menos que exquisita, al conformarse un mundo donde el gozo es anulado y sustituido por la supremacía de la voluntad, hace emerger como contrapartida el poder en su liderazgo desgarrador.

A propósito de esta situación lacerante, Centeno pone de manifiesto cómo la gesta auténtica acometida por T. E. significó para Ocampo no ya la legendaria rebelión en el desierto, sino el desafío máximo que él se impuso para sí desde lo secreto: el trascender de su voluntad frente a la propia finitud. Esta misma trascendencia es la protagonista acabada de la hazaña de Lawrence que Victoria, por su parte, descubre en Los siete pilares de la sabiduría. En este relato, Ocampo observa los avatares de una voluntad que se caracteriza por llevar a cabo un completo y sistemático dominio sobre la propia existencia. Voluntad de poder - expresa Centeno - que sólo encuentra límite a su expansiva plenitud cuando se enfrenta contra su condición mortal. Semejante desazón reviste de impronta teleológica la composición de 338171 T. E., pues en ella se intenta no sólo rescatar sino también conferir un sentido unitario a las diversas aporías que azuzan el espíritu de Lawrence en su doble figura de actor y espectador.

En un orden metodológico de consideraciones, Centeno encara el análisis del escrito de Ocampo desde el universo teórico de la filosofía del arte. Ella advierte que, en las no muy extensas pero sí densas páginas de 338171 T. E., está registrado el rol de Victoria como testigo del arte y, además, como lúcido testigo de su peculiar relación con la propia experiencia poética. Debido a estas razones, Centeno asevera que la filosofía puede asumirse como marco aperceptivo formal, necesario aunque implícito, en cada obra. Los supuestos teóricos y metodológicos adoptados por Centeno son expuestos con asidero al comienzo de su trabajo. Ella intenta aportar a la comunidad académica una perspectiva de elucidación crítica que, esta vez desde la estética, se asome como posibilidad de complementar y enriquecer el campo estrictamente literario en el que se funda la obra estudiada.

En vista de estos lineamientos, Centeno se vale de dos recursos procedimentales que promueven una mejor interpretación de su objeto de estudio. El primero se refiere a los "horizontes hermenéuticos", por medio del cual se busca establecer los límites y alcances de la interpretación en relación con las posibilidades proyectadas en el comprender. En segundo lugar, su investigación adopta como categorías analíticas los principios de 
la "estética de trama y urdimbre", excogitados por E. Albizu. El empleo de estos conceptos se adecua de manera conveniente al material escogido y justifica su pertinencia en la índole misma de la obra analizada. De esta manera, el trabajo propiciado por nuestra autora ahonda en el origen particular del acontecer estético del texto de Ocampo, desarrollado a favor de una labor hermenéutica que reconoce sustento teórico en Verdades del Arte de Albizu (2000), sin dejar de acudir por ello a otros trabajos integrantes de su variado repertorio escrito. En el planteo de esta labor, la estructura sobre cuya base se organiza la tesis seguida por Centeno coincide con el diseño de los distintos planos de significancia del "diagrama de la dialéctica semiológica de la obra de arte", tal como lo denomina el pensador argentino.

Una vez planteado el punto de partida y diseñado el instrumento de análisis, el estudio de Centeno se aboca a la consideración de los distintos planos de significancia que integran el "diagrama de la dialéctica semiológica de la obra de arte" y que ella va descubriendo como núcleos efectivos y operantes en el texto de Ocampo. Tomando como punto de partida el material pre-significante, son determinados por Albizu (2000: 153 ss.) cuatro planos del significante: (1) código formal, (2) estilo, (3) realidad formal stricto sensu y (4) las nuevas búsquedas formales; junto con cuatro planos respectivos del significado: (1') significado primario, que equivale a los motivos y su composición; ( $\left.2^{\prime}\right)$ secundario, relacionado con las formas culturales que dan de sí imágenes (historias y alegorías); ( $\left.3^{\prime}\right)$ terciario, que alumbra desde los principios metafísicos los símbolos y mitos conformadores el tejido textual y, finalmente, ( $\left.4^{\prime}\right)$ el cuarto plano del significado: el tiempo.

Centeno dilucida desde el postulado axial del encuentro intersubjetivo cuál es el código formal característico de la obra de Ocampo. Como se ha dicho supra, este código es el de un testimonio. A partir de él, se derivan en consecuencia los significados primarios, secundarios, terciarios y cuaternarios, en estrecha relación con los planos del significante ya mencionados.

En relación con el nivel simbólico, Centeno somete a una elucidación sumamente valiosa la gráfica que acompaña la primera edición de 338171 T. E., representada por las dos espadas. En ellas se cifra - según el examen ejecutado por Centeno - todo el sustento épico de la vida y obra de Lawrence. Pero también del de Victoria, porque ese símbolo de 
las dos cimitarras curvas entrecruzadas trascenderá los márgenes de la obra escrita acompañando a la escritora hasta los últimos momentos de su vida, en forma de broche ajustado a la solapa de su traje, como recordatorio permanente de su alianza espiritual.

Otra imagen relevante tematizada por Centeno es la del desierto, como lugar de encuentro y revelación de lo absoluto. El yermo exige el reconocimiento de la propia finitud y la intrínseca dependencia, un ámbito de esperanza y sublimación que per definitionem rebosa de silencio, escucha y apertura. La idea de libertad también se yergue como un tópico central del análisis elaborado por la autora. Relacionada con la dimensión ética y al precio de una purificación trágica, la libertad se entiende en estos horizontes hermenéuticos como la transformación de una voluntad omnímoda en disponibilidad para lo otro que ella.

Conviene dedicar tan siquiera un breve párrafo al último plano del significado, precisamente, al tiempo, en cuyo nivel la obra de arte toca fondo. La indagación acerca del contenido que adopta el tiempo qua ausencia no es allende la obra de arte, pues el tiempo no es un atributo más de la misma junto con otros; antes bien, actúa en ella como su hontanar germinal. En virtud de este significado, que resulta ser el más recóndito, la obra está abierta al fundamento de lo real; si bien, para alcanzarlo, es necesario calar en lo profundo de su lógica operatoria. En el estudio de Centeno, la temporalidad deviene estructura kairológica en la que el pensamiento revierte sobre sí mismo en numerosas perspectivas. A propósito de ello, cita los versos que se ubican a modo de epígrafe de Los siete pilares de la sabiduría. Se trata de una pieza sencilla pero de significación meridiana dado que allí - según dilucida Centeno - T. E. manifiesta su deseo crucial de sustraerse al paso del tiempo por acción de la palabra: "Yo te quería, por eso atraje a mis manos esas mareas de hombres / y escribí con estrellas mi voluntad en el cielo. / Para ganarte la libertad, la casa digna, la de los siete pilares, y que tus ojos pudieran brillar para mí cuando llegáramos" (Lawrence, 1963: 5).

Por último, cabe señalar que la perspectiva adoptada por el estudio de Centeno se justifica a partir de las características propias de toda obra de arte, conviene a saber: circularidad y ocasionalidad, en la medida en que operan como sus motivos más distinguidos. Circularidad, porque el retorno de la obra sobre la efectividad histórica genera numerosas y siempre renovadas constelaciones de posibles significados; ocasionalidad, 
porque la significación se determina en su contenido desde la oportunidad en que es experimentado el poetizar.

Para finalizar, debe decirse que sin dejar de alcanzar la objetividad crítica imprescindible para toda investigación, el estudio de Rosalía Centeno hace gala de un auténtico dominio del lenguaje poético. De acuerdo con todo lo expuesto, este nuevo ejemplar constituye un aporte representativo a los estudios sobre Victoria Ocampo ya en curso y ofrece la posibilidad de participar en la experiencia del reconocimiento, que cimentó la escritora argentina al recuperar la figura de Lawrence.

\section{Referencias bibliográficas}

ALBIZU, E. (2000) Verdades del Arte. Buenos Aires: Baudino-UNSAM.

CENTENO DE DE Hoyos, R. (2014) Horizontes hermenéu-ticos y autotransparencia del espíritu en la obra 338171 T. E. de Victoria Ocampo. Mendoza: Allubgraf.

LAWRENCE, T. E. (1944) SevenPillars of Wisdom. London: Jonathan Cape LTD.

- - - - (1963) Los siete pilares de la sabiduría. Traducción de Victoria Ocampo. Buenos Aires: Sur.

OCAMPO, V. (1942) 338171 T. E. Buenos Aires: Sur.

PLATO (1903) Platonis Opera, ed. John Burnet. Oxford: Uni-versity Press. RICOEUR, P. (1999) Historia y Narratividad. Barcelona: Paidós.

VIÑUELA, C. (2004) Victoria Ocampo. De la búsqueda al conflicto. Mendoza: EDIUNC. 